\title{
Usos de Foucault na revista Psicologia \& Sociedade (1986-2017)
}

\author{
Foucault uses in Psicologia \& Sociedade journal (1986-2017)
}

\begin{abstract}
Amanda Gabriella Borges Magalhães; Flávia Cristina Silveira Lemos
Universidade Federal do Pará.
\end{abstract}

\section{RESUMO:}

Neste estudo investigamos a recepção do filósofo francês Michel Foucault (1926-1984) na Psicologia Social brasileira a partir da análise dos usos do autor nas publicações da Revista Psicologia \& Sociedade (1986-2017), da Associação Brasileira de Psicologia Social (ABRAPSO). O corpo documental desta pesquisa histórica foi composto de 90 artigos que citaram nominalmente o autor. Caracterizou-se a produção levantada quanto ao ano de publicação, distribuição geográfica, vinculações institucionais das autorias, temas e delineamentos dos estudos. Foram encontradas citações do filósofo durante todo o recorte temporal estabelecido, sendo a primeira em 1986, e o ano com maior frequência, 2012. Os trabalhos ligam-se majoritariamente a Instituições de Ensino Superior Públicas brasileiras, especialmente das regiões Sudeste e Sul (74,4\%). Dos 90 estudos, 54 foram teóricos, e 36, empíricos. Versaram sobre Reflexões conceituais e epistemológicas, Políticas Públicas, Reflexões sobre a Psicologia, Subjetivação, Gênero/Sexualidade/Feminismo, Infância/Adolescência/Juventude, Arte-Política e Outros.

Palavras-chave: História da Psicologia Social; Psicologia \& Sociedade; Foucault.

\section{ABSTRACT:}

This research investigates the reception of french philosopher Michel Foucault (1926-1984) in Brazilian Social Psychology by analyzing the author's uses in the publications of Psicologia \& Sociedade Journal (1986-2017), produced by Brazilian Association of Social Psychology (ABRAPSO). Ninety articles witch cited the author's name has been analysed. Year of publication, geographic distribution, institutional links of authorship, themes and study designs were considered in analysis. Citations of philosopher's name was found throughout all the time period considered in this study: the first happened in 1986, and the year with most frequently citations is 2012. The works are mostly related to Brazilian Public Higher Education Institutions, especially in the Southeast and South (74, 4\%). Of the 90 studies, 54 were theoretical and 36 empirical. They dealt with Conceptual and Epistemological Reflections, Public Policy, Reflections on Psychology, Subjectivation, Gender / Sexuality / Feminism, Childhood / Adolescence / Youth, Art-Politics, and Others.

Key-words: History of Social Psychology; Psicologia \& Sociedade; Foucault. 
O filósofo francês Michel Foucault (1926-1984) faz-se frequentemente presente nas produções acadêmicas de várias áreas de conhecimento, para muito além da filosofia. Seu trabalho é considerado como "ponto estratégico na conjuntura teórica [francesa e] internacional" (BERT, 2013, p. 8). Seus usos são constantes, também, em uma série de debates que fogem à seara acadêmica, sendo referência utilizada por diversos movimentos sociais ligados aos inúmeros assuntos nos quais sua produção toca: a sexualidade, a prisão e demais espaços disciplinares, a medicalização dos corpos, as práticas de resistência e liberdade.

No Brasil, Foucault é interlocutor comum quando se trata de políticas públicas, de gênero e orientação sexual, de insurgências coletivas e individuais na transversalidade entre a macro e a micropolítica, de processos de subjetivação, entre tantos outros temas. Como efeito dessa ampla apropriação, a recepção de seu pensamento vem sendo estudada por pesquisadores de diversas áreas com o intuito de analisar as ressonâncias de sua obra na constituição destes campos de saber.

Dentre os estudos mais recentes, podemos destacar: na Educação, "A difusão do pensamento de Michel Foucault na educação brasileira: um itinerário bibliográfíco" (AQUINO, 2013) e "Os usos pedagógicos da noção de cuidado de si: um estudo sobre a recepção do pensamento tardio de Michel Foucault no campo educacional brasileiro" (SILVA, 2012); na História, “Genealogia de uma operação historiográfica: Edward Palmer Thompson, Michel Foucault e os historiadores brasileiros da década de 1980" (RAMOS, 2015); e nas Ciências Contábeis, "Movimento de teorias em campos interdisciplinares: a inserção de Michel Foucault na Contabilidade" (RICCIO; MENDONÇA NETO; SAKATA, 2007).

No caso da Psicologia, temos como referências importantes sobre este tema as pesquisas realizadas por Cavalcante et al. (2016) e Ferreira Neto et al. (2017), além da extensa produção de textos de psicólogos utilizando a obra de Foucault como base de suas investigações e práticas profissionais.

A pesquisa realizada por Cavalcante et al. (2016) aponta que, dentre os artigos disponíveis na Biblioteca Virtual em Saúde (BVS-Psi), as articulações com operadores conceituais propostos por Foucault vêm aumentando de frequência desde o ano de 2001 (data da produção mais antiga dentre o conjunto analisado). Quanto aos temas trabalhados por estes 
estudos no recorte temporal de 2001 a 2013, encontram-se: (1) processos de subjetivação; (2) psicanálise, psicologia clínica e psicologia da saúde; (3) produção de conhecimento; (4) corpo.

Já o estudo de Ferreira Neto et al. (2017) sobre os encontros de nossa ciência com o campo filosófico, apontou Foucault como o filósofo mais citado nos estudos em psicologia no Brasil. Esta informação foi produzida a partir de um levantamento por eles realizado na plataforma Scientific Electronic Library Online (SciELO) no ano de 2014, mesclando os descritores "Filosofia" e "Psicologia", aparecendo "Foucault com destaque em primeiro lugar com 89 entradas, seguido por Deleuze com 32 e Adorno com 26" (FERREIRA NETO et alii., 2017: 2).

No mesmo estudo, os autores apontam que "os periódicos na SciELO que mais publicaram artigos, tendo Foucault como referência (...) têm identificação com a Psicologia Social" (FERREIRA NETO et alii., 2017: 2). Dentre estes, a revista Psicologia \& Sociedade, da Associação Brasileira de Psicologia Social (ABRAPSO) aparece em segundo lugar, com 13 publicações, logo atrás de Fractal/Revista do Departamento de Psicologia da UFF, com 19 artigos. Para fins desta análise, os autores consideraram as publicações disponíveis na plataforma até o ano de 2014 e fizeram a busca a partir dos descritores "Psicologia" e "Foucault", associados.

Uma vez que a revista da ABRAPSO se encontra indexada desde 2002 e a da UFF desde 2005, poder-se-ia inferir que a segunda produz bem mais com Foucault que a primeira. Porém, dentro do mesmo recorte, o número de artigos encontrados na Psicologia \& Sociedade em nossas buscas foi bem superior a este. A pesquisa foi realizada na plataforma SciELO, dentro da aba referente à revista, usando a palavra "Foucault" como descritor. Desta maneira, no recorte de 2002 a 2013, encontramos 43 artigos que utilizam o nome do autor em seus resumos, o que indica que os usos do filósofo francês no periódico são bem mais numerosos do que a pesquisa citada pôde abarcar.

Psicologia \& Sociedade também se destaca por sua importância histórica, que a torna estratégica quando se trata de analisar a produção da Psicologia Social de perspectiva crítica no Brasil. Apesar de ser apenas um dos veículos da comunicação científica neste campo, os usos de Foucault na Revista podem ser considerados indicativos pertinentes das formas com que o autor vem sendo apropriado na produção da crítica em Psicologia Social. 
Desde o segundo número da Revista, datado do ano de 1986, podemos perceber a presença do filósofo francês dentre os autores citados. Estes usos vêm se modificando no decorrer das décadas, conforme se lançam textos inéditos, ao passo que os acontecimentos do presente tensionam as ferramentas foucaultianas para tratar de novos temas, em tempos e espaços não vividos pelo autor. $\mathrm{Na}$ atualidade, o filósofo francês tem imenso destaque no campo da Psicologia Social, sendo utilizado tanto como referencial teórico - para tratar de temas como gênero e sexualidade, subjetivação, políticas públicas, entre outros - quanto metodológico, na realização de análises discursivas e pesquisas documentais.

Neste artigo, que é parte de uma dissertação de mestrado voltada à análise dos usos de Foucault na Psicologia Social brasileira, apresentamos alguns aspectos da recepção deste autor na Revista Psicologia \& Sociedade. A análise documental aqui realizada considerou todos os números publicados desde a criação da Revista, no ano de 1986, até 2017, e selecionou os artigos tendo como critério a citação do nome do autor. A partir da análise destes documentos iremos apresentar e discutir as características gerais das publicações, a saber: ano, autor (a) ou autores (as), vinculação institucional dos (as) mesmos (as), temas trabalhados e delineamentos utilizados nos estudos.

\section{Método}

Visto que os exemplares da Revista até o ano de 2001 encontram-se disponíveis no site da ABRAPSO ${ }^{1}$ em formato DOC, fez-se a busca por "Foucault" em cada arquivo. Todos os artigos contendo seu nome foram tomados como documentos para análise. As edições a partir de 2002 encontram-se na base de dados $\mathrm{SciELO}^{2}$, na qual a pesquisa foi realizada através do mecanismo de busca, também usando o nome do autor, "Foucault", sem outras especificações. Ressalta-se que, apesar de não termos selecionado um campo específico onde o nome do autor deveria constar na publicação, todos os artigos encontrados tinham "Foucault" dentre suas palavras-chave e muitos deles também no resumo ou título.

Dos noventa e um artigos encontrados, apenas um foi excluído do corpo documental por ter sido escrito em francês, língua não dominada pela pesquisadora. Compuseram, portanto, nosso conjunto de documentos para análise, noventa artigos escritos em português, espanhol e inglês. Os artigos foram lidos na íntegra e as informações sobre as categorias pertinentes à nossa investigação foram apropriadas a partir de fichas individuais de análise considerando os aspectos a serem observados em cada texto e uma tabela no EXCEL, para 
organizar as informações obtidas e facilitar a análise utilizando-se das ferramentas do programa.

Os artigos encontrados na busca estavam divididos entre 57 números diferentes da revista Psicologia \& Sociedade, dentre os 70 números que acessamos. O total de números publicados pelo periódico em questão desde sua fundação é 74. A diferença entre os valores representa os números publicados entre 1986 e 2001 que não estão arquivados no site da Associação e aos quais não tivemos acesso. Dos 21 números que compõem o periódico até 2001, acessamos 18 , o que compreende $85,7 \%$ da totalidade.

No recorte de 2002 a 2017, apesar da busca sem delimitações na plataforma, fomos direcionados às produções cujo nome do autor se encontrava no resumo e, em alguns casos, também no título e palavras-chave, o que indica a realização de usos mais aprofundados do filósofo. Não se pode afirmar, portanto, que nossa seleção abrange a totalidade dos trabalhos que citam Foucault na Revista Psicologia \& Sociedade. O número abrangido, porém, faz-se significativo e representativo para análise.

\section{Resultados}

\section{Distribuição temporal e geográfica das publicações}

A média de publicações citando nominalmente o autor na Revista, a partir do nosso recorte, é de 3,75 artigos por ano. Porém, como mostra a Figura 1, acerca da dispersão temporal das publicações com Foucault, esta média não é constante. 
Figura 1 - Publicações com Foucault por Ano.

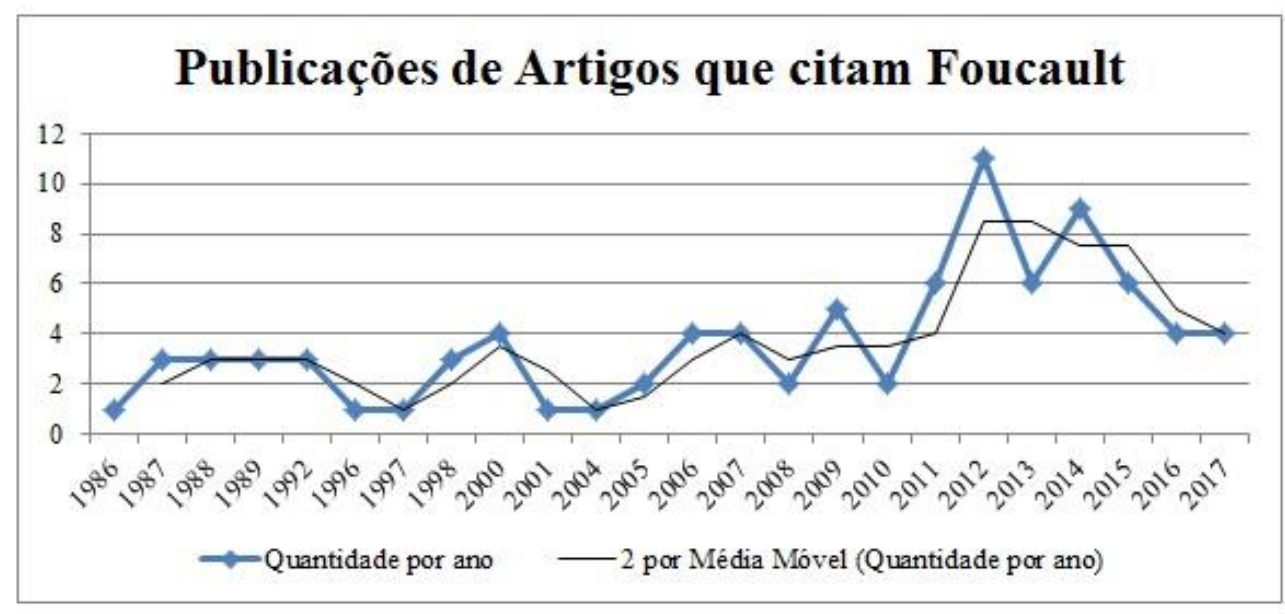

Fonte: Dados da Pesquisa.

Podemos perceber alguns altos e baixos no número de publicações no decorrer do período analisado. Em 2012, apresenta-se um pico de produções e, a partir de então, um aumento da média em relação à dos anos anteriores. Este aumento estende-se até 2017, quando a média retorna a quatro artigos/ano - do qual havia saído anteriormente.

O alto número de artigos publicados em 2012 deve-se à elaboração de um número especial, voltado para a discussão da judicialização da vida ${ }^{3}$, que foi produzido como desdobramento do "Primeiro Colóquio Internacional Michel Foucault", com este tema. O evento ocorreu na Universidade do Estado do Rio de Janeiro (UERJ) no mês de outubro de 2011, e contou com a presença de renomados pesquisadores que fazem uso das ferramentas foucaultianas em seu trabalho, como Jean François Bert ${ }^{4}$ e inúmeros intelectuais brasileiros, sobretudo da área da filosofia e da psicologia.

No corpo documental selecionado, composto de 90 publicações, estiveram envolvidos 125 autores, vinculados a 52 Instituições de todas as regiões do Brasil e de alguns outros países (Venezuela, México, Itália). Dentre elas, observamos trinta (57,69\%) Instituições de Ensino Superior (IES) Públicas, nove IES Comunitárias ${ }^{5}$ (17,31\%), nove IES Privadas $(17,31 \%)$ e quatro instituições $(9,61 \%)$ que se encaixam em outras classificações ${ }^{6}$.

Em relação à distribuição geográfica das produções, percebemos predomínio da participação de autores e instituições da região Sudeste, seguido dos da região Sul, o que 
coaduna com a comum divisão regional das publicações no Brasil (SIDONE et alii., 2016), e também na Revista (CRUZ; STRALEN, 2012).

A Tabela 1 apresenta detalhes da distribuição geográfica de artigos. Ressalta-se que, em razão de oito deles terem sido produzidos por autores de outros países, o número total que estamos considerando aqui é de 82 artigos.

Tabela 1- Distribuição geográfica dos artigos

\begin{tabular}{ccc}
\hline Distribuição geográfica & $\begin{array}{c}\text { Quantidade de artigos } \\
\text { produzidos }\end{array}$ & Porcentagem \\
\hline Somente Sudeste & 40 & $48,78 \%$ \\
Somente Sul & 21 & $25,60 \%$ \\
Somente Nordeste & 8 & $9,75 \%$ \\
Somente Norte & 3 & $3,65 \%$ \\
Somente Centro-Oeste & 1 & $1,21 \%$ \\
Sudeste e Nordeste & 1 & $1,21 \%$ \\
Sudeste e Norte & 3 & $3,65 \%$ \\
Sudeste e Sul & 3 & $3,65 \%$ \\
Sul e Nordeste & 2 & $2,43 \%$
\end{tabular}

Fonte: Dados da Pesquisa.

Conforme mostra a tabela acerca da distribuição geográfica de artigos, aproximadamente metade deles foi produzida por autores ligados a instituições da região Sudeste, seguidos de quase $25 \%$ vinculados à região Sul. Essa porcentagem tende a aumentar se reduzirmos as categorias de distribuição geográfica somando todas as participações em artigos, contando as parcerias inter-regionais, conforme demonstrado na Tabela 2. Neste caso, é notória a presença da região Sudeste em mais da metade do total de artigos produzidos no Brasil $(n=82)$, e mesmo da totalidade de trabalhos analisados $(n=90)$. 
Tabela 2 - Distribuição geográfica dos artigos por cada região

\begin{tabular}{ccc}
\hline $\begin{array}{c}\text { Distribuição } \\
\text { geográfica }\end{array}$ & $\begin{array}{c}\text { Quantidade de artigos nos quais } \\
\text { participa }\end{array}$ & Porcentagem \\
\hline Sudeste & 47 & $57,31 \%$ \\
Sul & 26 & $31,70 \%$ \\
Nordeste & 11 & $13,41 \%$ \\
Norte & 6 & $7,31 \%$ \\
Centro-Oeste & 1 & $1,21 \%$ \\
\hline
\end{tabular}

Fonte: Dados da Pesquisa.

Pistas para a compreensão dessa hegemonia regional podem ser encontradas revisitando a história da Psicologia Social no Brasil, da ABRAPSO ou da recepção do Foucault em nosso país. Os acontecimentos ligados à história da Psicologia Social são majoritariamente registrados no e desde o Sudeste/Sul, assim como a maior concentração de psicólogos no Brasil, o surgimento das primeiras graduações e pós-graduações, congressos e também a maior parte das visitas de Foucault ao Brasil. Porém, antes disso, a concentração destes acontecimentos nas regiões Sudeste/Sul aponta para a disparidade regional na distribuição de recursos científicos e tecnológicos (SIDONE et alii., 2016), que perpassam a trajetória de constituição da rede de universidades e pesquisas no Brasil.

No eixo Sul-Sudeste, o núcleo de produção de ciência desenha-se entre São Paulo, Rio de Janeiro, Minas Gerais e Rio Grande do Sul. No triênio 2007-2009, as produções destes estados corresponderam a $64,2 \%$ do total nacional - o que representou uma redução em relação ao período de 1992-1994, onde essa porcentagem ultrapassou os 76\% da produção científica no país (SIDONE et alii., 2016).

A concentração por Estados também pode ser percebida se observarmos a Figura 2, com a dispersão das participações em artigos produzidos pelo território nacional. Considerada a existência de publicações realizadas por instituições de mais de um Estado, optamos por contabilizar unidades de participação, ao invés do número de artigos. A um mesmo estudo puderam ser associadas duas ou três unidades de participação, dependendo do número de Estados envolvidos. A cada Estado foi atribuída uma unidade de participação por cada artigo 
em que se fez presente. Por conta disso, a soma das unidades apresentadas na legenda é superior ao número de artigos $(\mathrm{n}=106)$.

Figura 2 - Distribuição geográfica de participação nos artigos

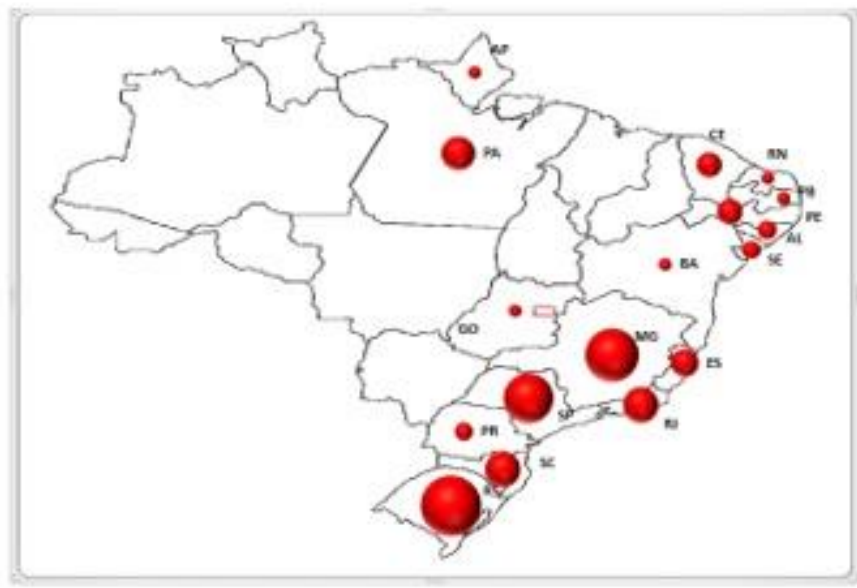

Fonte: Dados da Pesquisa.

Legenda: Rio Grande do Sul (UFRGS, PUC-RS, Centro Universitário Franciscano Santa Maria - RS, Faculdade Cenecista de Osório, UNIRITTER, Universidade de Santa Cruz do Sul, URI): 23; Minas Gerais (UFMG, PUC MINAS, UFJF, CES-JF, FIOCRUZ-MG, UNIMONTES): 18; São Paulo (UNESP/Assis, PUC-SP, USP, UNICAMP, UNIFESP, Universidade Anhanguera de São Paulo, Universidade São Judas Tadeu-SP): 16; Rio de Janeiro (UFF, UERJ, UFRJ, PUC-RIO, UNIRIO): 8; Santa Catarina (UFSC, Centro Universitário Estácio de Sá/SC): 8; Pará (UFPA/Belém; UFPA Abaetetuba): 7; Espírito Santo (UFES, Prefeitura de Vila Velha): 5; Ceará (UFC, UNIFOR): 4; Pemambuco (PUC-PE, UFPE, Faculdade Pio Décimo, Universidade Tiradentes): 4; Paraná (PUC-PR, UEL): 2; Alagoas (UFAL): 2; Sergipe (UFS): 2; Bahia (UFBA): 1 ; Paraiba (UFPB): 1 ; Rio Grande do Norte (UFRN): 1;Amapá (SEAMA): 1 ; Goiás (UFG-Catalão):1.

A partir do mapa, podemos perceber que os estados do Rio Grande do Sul, Minas Gerais, São Paulo e Rio de Janeiro destacam-se nas produções de artigos em Psicologia Social utilizando Foucault no Brasil, sobretudo a partir das Universidades Federais. Estes estados somam $61,3 \%$ das unidades de participação nas publicações $(n=106)$.

Em sua análise da produção científica da Psicologia \& Sociedade (1986-2007), Cruz (2008) aponta que durante o recorte de sua pesquisa, "foi detectada uma relação direta entre a produção e o local onde a revista estava sendo organizada" (CRUZ, 2008: 112), tanto no que se considera sua primeira fase (1986-1992), quanto na segunda, iniciada em 1996, até o momento em que se estendeu a pesquisa do autor (1996-2007). 
No primeiro período, a organização esteve vinculada majoritariamente a Minas Gerais. No segundo, a São Paulo, tendo como editor geral Antônio da Costa Ciampa (1996-2001), e Rio Grande do Sul, com Cleci Maraschin na editoria (2002-2007). Após isto, tivemos como editoras gerais Kátia Maheirie, da UFSC (2008-2011), Cláudia Mayorga, da UFMG (20122015) e Luciana Kind, da PUC Minas (2016-2019). Importante ressaltar que foi no ano de 2005 que o periódico aderiu ao SEER (Sistema Eletrônico de Editoração de Revistas), possibilitando maior inclusão de pesquisadores de diferentes Estados na comissão editorial (MARASCHIN, 2007).

A partir de 2009, começam a se inserir nas produções Unidades Federativas de fora do eixo Sul-Sudeste. Dos doze artigos vinculados exclusivamente a estados de outras regiões, onze datam de 2009 e anos posteriores. A primeira, do ano de 1989, tem como autor Genaro Ieno Neto, ligado à Universidade Federal da Paraíba, reconhecida por seu antigo Programa de Pós Graduação em Psicologia Social, existente desde a década de 1980, que se fez bastante presente no periódico da ABRAPSO durante a sua primeira fase (1986-1992) (CRUZ; STRALEN, 2012).

A quebra da exclusividade de publicações do eixo Sul-Sudeste em 20 anos se deu a partir da produção de uma Universidade nordestina (UNIFOR) em parceira com uma do Sul ${ }^{7}$ (UFRGS), e de uma Instituição do Norte (UFPA) em conjunto com uma do Sudeste ${ }^{8}$ (UNESP/Assis), no mesmo ano. Em comum entre as autoras vinculadas ao Norte e Nordeste temos o fato de que tiveram sua formação (graduação, mestrado e doutorado) em universidades do Sul-Sudeste. Esta se mostrou uma característica comum na produção analisada. Podemos considerar a migração de pesquisadores do Sul-Sudeste, de Instituições reconhecidas pelos estudos foucaultianos, para as outras regiões do Brasil, como um fator importante da dispersão dos usos de Foucault, sobretudo na Psicologia Social.

Sidone et alii. (2016) apontam o aumento da colaboração entre pesquisadores como fundamental para a desconcentração regional das produções científicas, timidamente em curso no Brasil. Embora essa colaboração não se dê apenas no nível das coautorias e inclua também organização de eventos e outras atividades, a produção conjunta de artigos, resumos completos e capítulos de livros tem sido bastante estratégica no aumento qualitativo e quantitativo das produções científicas no mundo (SIDONE et alii., 2016).

Observando o quadro abaixo podemos perceber que, dos 90 artigos analisados, 46 $(51,1 \%)$ foram escritos por apenas um autor e $44(48,8 \%)$ contaram com coautorias (22 delas 
entre membros da mesma Instituição e as demais 22 entre pesquisadores de Instituições diferentes). $\mathrm{O}$ alto número de autorias individuais na Revista provavelmente se liga ao grande número de trabalhos teóricos nela publicados (CRUZ, 2008), conforme veremos mais à frente. Apesar disso, porém, as coautorias vêm se fazendo cada vez mais presentes.

Dentro de nossa amostra, é no ano de 2005 que se iniciam as coautorias. Até lá, temos 25 artigos produzidos por apenas um autor. A partir daí, porém, essa forma de produção diminui de frequência. Dos outros 65 artigos, apenas 21 foram produzidos individualmente. E destes, 9 são decorrentes de comunicações feitas no já citado "II Colóquio Internacional Michel Foucault: a judicialização da vida", o que justificaria a individualidade das autorias.

Figura 3 - Quantidade de autores nos artigos

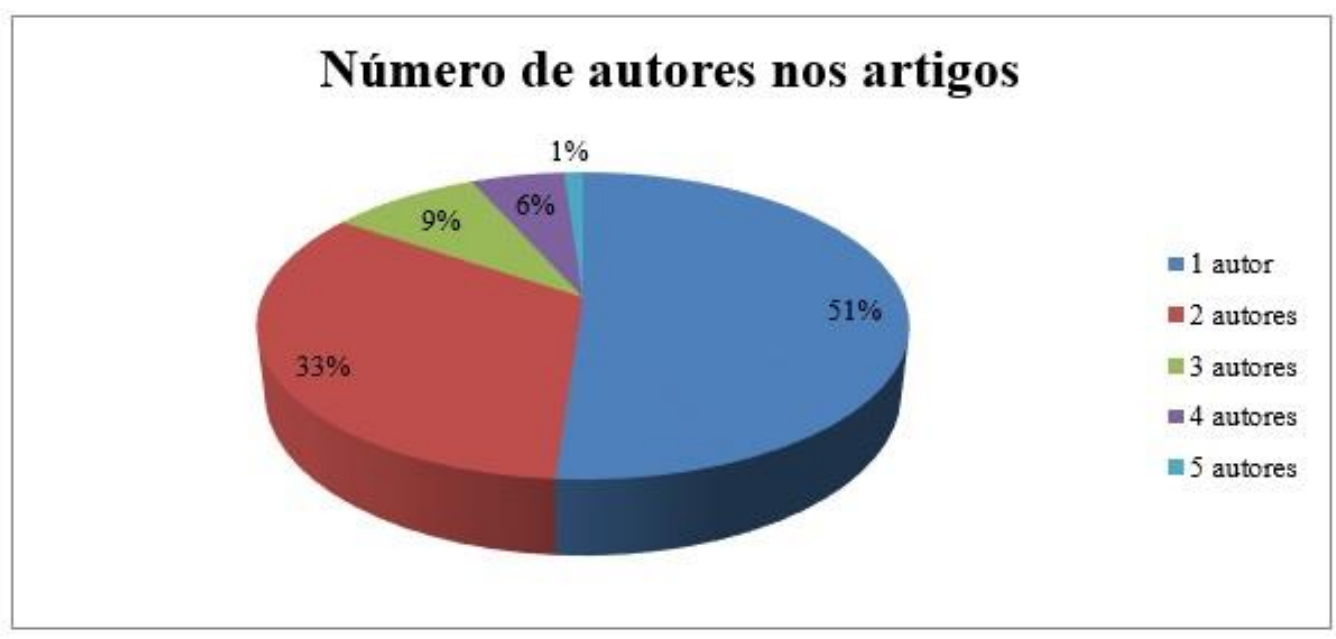

Fonte: Dados da Pesquisa.

Segundo um estudo de Ribas Jr. et al. (2009), nas pesquisas em Psicologia Social no Brasil, até 1986, a média de autores por artigo era de 1,5, número este que sobe para 2,5 em 2006. Segundo os autores, isto pode ser explicado pelo aumento da quantidade de Programas de Pós-Graduação ocorrido nestas décadas e pelo incentivo à produção coletiva por parte das agências de fomento.

A maior parte dos pesquisadores (85\%) participou da publicação de apenas um artigo, o que pode indicar uma ligação casual com o tema/autor trabalhado e também caracterizar o grande movimento de incorporação de coautorias. A porcentagem de autores envolvidos na publicação de mais de um artigo é de: $11 \%$, para dois trabalhos; $1 \%$, para três; e $2 \%$, para 
quatro. Apenas uma pesquisadora apresenta número maior que este (6 artigos). Os autores que mais publicaram estão presentes na Tabela 3.

Tabela 3 - Autores com três ou mais artigos publicados

\begin{tabular}{|c|c|c|c|}
\hline Autores & Instituição & Número de Artigos & Ano de Publicação \\
\hline $\begin{array}{c}\text { Prof. }{ }^{\text {D }} \text { Dr }^{\mathrm{a}} \text { Flávia } \\
\text { Lemos }\end{array}$ & UFPA & 6 & $\begin{array}{c}2009,2011,2012, \\
2014,2015,2016\end{array}$ \\
\hline $\begin{array}{c}\text { Prof. }{ }^{\mathrm{a}} \text { Dr. }{ }^{\mathrm{a}} \text { Neuza } \\
\text { Guareschi }\end{array}$ & UFRGS & 4 & $\begin{array}{c}2000,2011,2013, \\
2014\end{array}$ \\
\hline $\begin{array}{c}\text { Prof. Dr. Kléber } \\
\text { Prado Filho }\end{array}$ & UFSC & 4 & $1987,2007,2011$, \\
\hline $\begin{array}{c}\text { Prof. }{ }^{\mathrm{a}} \text { Dr. }{ }^{\mathrm{a}} \text { Lília } \\
\text { Lobo }\end{array}$ & $\begin{array}{c}\text { PUC-Rio (1992); } \\
\text { UFF(2006, 2012) }\end{array}$ & 3 & $1992,2006,2012$ \\
\hline $\begin{array}{c}\text { Prof. Dr. Henrique } \\
\text { Caetano Nardi }\end{array}$ & UFRGS & 3 & $2007,2014,2014$ \\
\hline
\end{tabular}

Fonte: Dados da Pesquisa.

Cruz (2008), em sua investigação sobre a produção da Revista de 1986 a 2007, percebeu uma ligação entre as instituições às quais os autores que mais publicaram se vinculavam e a localização da editoria da revista. Em relação aos autores que mais publicaram usando Foucault na Revista, não percebemos esta relação. Isso pode tanto ser um reflexo da não vinculação direta entre os responsáveis editoriais do periódico com os estudos foucaultianos - pelo menos até o ano de 2007 (período até o qual se estendeu a pesquisa supracitada) - quanto um indicativo de que, nos últimos anos, essa relação entre localização dos editores e concentração geográfica das publicações não seja mais evidente.

Grande parte das produções dos autores que compõem a tabela acima foram feitas em coautoria com outros pesquisadores, principalmente a partir da dinâmica orientador/orientando. Duas delas, Prof. ${ }^{a}$ Dr. ${ }^{a}$ Flávia Lemos e Prof. ${ }^{a}$ Dr. ${ }^{a}$ Neuza Guareschi, também com colaborações inter-regionais (Norte-Sudeste e Sul-Nordeste, respectivamente).

A partir do resumo de seus currículos lattes, disponíveis na plataforma do $\mathrm{CNPq}^{9}$, observamos que quatro dos cinco pesquisadores compreendem em seu campo de pesquisa a temática das políticas públicas, sobretudo a partir das discussões sobre saúde e educação, em 
relação com modos de subjetivação contemporâneos. Isso também se faz evidente observando-se os grupos de estudo coordenados por eles: Psicologia Social e Política: transversalizando filosofia, história e educação (Flávia Lemos); Grupo de Pesquisa Estudos Culturais e Modos de Subjetivação, e Núcleo E-politcs - Estudos em Políticas e Tecnologias Contemporâneas de Subjetivação (Neuza Guareschi); Saúde Mental e Trabalho, e Políticas Públicas e Produção de Subjetividade (Henrique Nardi) ${ }^{10}$. A exceção é Kléber Prado Filho, que, pela abordagem mais teórica dos trabalhos, apresenta $75 \%$ de suas produções sem coautoria e descreve seu trabalho a partir de uma linha mais conceitual, utilizando Michel Foucault e relacionando com a Psicologia.

A formação dos pesquisadores, cuja maioria teve graduação em psicologia, envolve outras áreas do saber relacionadas à saúde, à educação, à sociologia e à história. Esta característica se mostrou comum na trajetória dos autores que produziram os artigos analisados. Isso porque, sabendo que nem todos os artigos trouxeram informações sobre a trajetória formativa dos autores, não pudemos fazer um diagnóstico completo da distribuição entre áreas. Pode-se indicar, porém, algumas pistas.

A formação, em nível de graduação, mestrado e doutorado, foi majoritariamente na área de psicologia. Destaca-se, porém, a grande ocorrência de pós-graduações em Educação, Saúde (Pública, Coletiva, e da Criança e do Adolescente, Medicina Preventiva), Sociologia e Filosofia, respectivamente. No que tange à Educação, vale destacar a forte presença do Programa de Pós-Graduação da UFRGS, o que coaduna com os achados de Aquino (2013) sobre a difusão do pensamento de Foucault nesta área. Em sua pesquisa, o autor aponta que "a maior frequência de publicações relacionadas a Foucault é encontrada em Educação e Realidade, periódico ligado à UFRGS, em cuja Faculdade de Educação foram disparadas as pesquisas em torno do pensador francês e que (...) continua a sediá-las com regularidade" (AQUINO, 2013:313).

Também se fazem presentes como áreas de formação: História, Psicanálise, Linguística e Língua Portuguesa, Música, Administração e Matemática Pura. Esta multiplicidade de áreas de diálogo reflete a transdisciplinaridade da produção que dialoga com a Psicologia Social no Brasil, o que também se mostra a partir dos conteúdos dos estudos analisados. 


\section{Temas e delineamento dos estudos}

Como afirmam Ferreira Neto et alii. (2017: 6), "o grande número de artigos de delineamento teórico parece ser uma tendência de nossa área", o que se atesta pela disparidade no número de artigos teóricos encontrados em sua análise sobre os artigos que relacionam Foucault e a Psicologia, e que também é corroborado por Cruz (2008), na produção geral da Revista até 2007. Nestas pesquisas, assim como na nossa, os estudos teóricos representam em torno de $60 \%$ do total, como se pode perceber na Tabela 4 .

Tabela 4 - Delineamento dos estudos

\begin{tabular}{cccc}
\hline Delineamento & $\begin{array}{c}\text { Quantidade } \\
(\%)\end{array}$ & Detalhamento & $\begin{array}{c}\text { Quantidade } \\
(\%)\end{array}$ \\
\hline \multirow{2}{*}{ Teórico } & 54 & Teórico-Temático & $37(41,1 \%)$ \\
& $(60 \%)$ & Teórico-Conceitual & $16(17,8 \%)$ \\
Empírico & 36 & Pesquisa Bibliográfica & $1(1,1 \%)$ \\
& $(40 \%)$ & Análise de Documentos & $19(21,1 \%)$ \\
& & Pesquisa de campo & $11(12,2 \%)$ \\
& & Relato de Experiência & $5(5,5 \%)$ \\
& & Estudo de Caso & $1(1,1 \%)$ \\
\hline
\end{tabular}

Fonte: Dados da Pesquisa.

A produção de categorias temáticas que pudessem enquadrar a diversidade de temas trabalhados não foi tarefa simples. Durante nossa leitura e criação das categorias, tomamos como relevante o foco central do artigo. Para isso, foi fundamental a observação do objetivo delimitado e, quando necessário, do titulo e palavras-chave, para avaliar os descritores atribuídos ao trabalho.

As categorias utilizadas por Zanella (2009) e Cruz e Stralen (2012) relacionadas a diagnósticos da produção do periódico Psicologia \& Sociedade, assim como das pesquisas de Ferreira Neto et alii. (2017) e Cavalcante et alii. (2016) sobre a apropriação de Foucault na Psicologia no Brasil, serviram de base para a criação das categorias temáticas elaboradas nesta análise. Todos os temas indicados pelos estudos supracitados foram encontrados nos artigos que compuseram nosso corpo documental. Inspirados nessas categorias e baseados em 
nossas observações acerca das publicações optamos por classificá-las em oito grupos, listados abaixo.

Tabela 5 - Categorias temáticas

\begin{tabular}{cc}
\hline Categorias Temáticas & Quantidade de artigos (\%) \\
\hline Reflexões conceituais e epistemológicas & $23(25,5 \%)$ \\
Políticas Públicas & $22(24,4 \%)$ \\
Reflexões sobre a Psicologia & $13(14,4 \%)$ \\
Subjetivação & $12(13,3 \%)$ \\
Gênero/Sexualidade/Feminismo & $6(6,7 \%)$ \\
Infância/Adolescência/Juventude & $5(5,5 \%)$ \\
Arte-Política & $4(4,4 \%)$ \\
Outros & $5(5,5 \%)$ \\
\hline
\end{tabular}

Fonte: Dados da Pesquisa.

Na categoria mais numerosa, voltada para Reflexões Conceituais e Epistemológicas, alocamos estudos que tiveram como objetivo discutir um conceito dentro da obra de um ou mais autores, ou mesmo algum texto de determinado autor. Em se tratando de uma revista de Psicologia Social, muitos dos trabalhos também realizaram, após a discussão do conceito, sua contextualização dentro de algum tema, e isto não foi considerado critério de exclusão da categoria. Também compuseram esta categoria estudos que se focam no debate entre aproximações e repulsões teóricas de autores ou perspectivas epistemológicas.

$\mathrm{Na}$ segunda categoria, foram incorporados estudos que abordam práticas relacionadas a diversas Políticas Públicas, no campo da educação, educação sexual, segurança, saúde coletiva, saúde mental, assistência social, questões relacionadas à drogadição, gestão do lixo, judicialização da vida, entre outros. O principal critério de inclusão foi que o foco se direcionasse para o serviço, a lei ou o direito trabalhado, tendo a discussão sobre a gestão da população como questão principal. As temáticas aqui envolvidas abarcam também outras categorias temáticas, como Gênero/Sexualidade/Feminismo e Infância/Adolescência/Juventude. A diferenciação se deu justamente tomando como critério a importância dada ao debate da política pública ou ao tema. 
Nas Reflexões sobre a Psicologia, classificaram-se artigos cujo enfoque foi este campo, colocando a psicologia em questão do ponto de vista teórico, histórico, de suas práticas interventivas ou de pesquisa.

Nos estudos sobre Subjetivação enquadraram-se artigos voltados para a produção de um diagnóstico das formas de subjetivação. Sob este termo, estamos aqui considerando uma infinidade de outros, como identidade, subjetividade, tecnologias de si, que variam de acordo com a perspectiva teórica utilizada no trabalho. Este tema atravessa muitas discussões de outras categorias, uma vez que se trata de um periódico de psicologia, porém nem todos têm na subjetivação em si o foco de investigação.

A categoria Gênero/Sexualidade/Feminismo incorporou trabalhos que trataram das noções de sexualidade (do ponto de vista discursivo ou das produções corporais e subjetivas relacionadas) e das questões de gênero, com a discussão da produção da mulher, além de intervenções feministas. Estes trabalhos não tiveram seu foco em políticas públicas com este recorte, mesmo que alguns tenham sido realizados em estabelecimentos ligados a elas.

No grupo Infância/Adolescência/Juventude foram alocados artigos que trataram especificamente destas fases do desenvolvimento, às vezes juntas, às vezes separadas. Tratouse desse grupo majoritariamente a partir de estratégias de seu governo ou de sua produção, tendo como foco outras práticas que não as das políticas públicas de Estado diretamente.

A última categoria, Arte-Política, é composta por artigos que questionam a arte e suas potencialidades no que tange à produção de intervenções políticas, educacionais ou de saúde, em práticas não capturadas pelas políticas públicas de Estado, mas que se aproximam das práticas de governo e promovem subjetivação.

Todos os artigos que não se enquadraram nos grupos acima descritos foram direcionados para a categoria "Outros". Nela, encontram-se artigos que tratam sobre: a relação dos intelectuais com os movimentos sociais; interculturalidade; velhice; uma análise das relações de poder na obra de Machado de Assis; e dos modos de aparição de Foucault na imprensa brasileira.

O grande número de trabalhos cujo objetivo é refletir acerca do campo da psicologia, assim como da Psicologia Social - seja a partir de aspectos teóricos e históricos, conforme observado na pesquisa de Cruz (2008), ou sobre os fazeres e suas implicações - pode ser relacionado com esta atmosfera reflexiva dos anos 80 e 90 do século passado, em que a psicologia necessitou reinventar-se para acessar novos postos de trabalho em meio ao 
processo de redemocratização. Nestas décadas surgem e/ou se consolidam uma série de novas especialidades e formas de atuação, como a psicologia jurídica, do esporte, ligada ao marketing e também intervenções nos campos da saúde pública e coletiva, bem como nas comunidades (BOMFIM et alii., 2010).

Já a categoria "Políticas Públicas" começa a aparecer apenas a partir do ano de 2004 e mantém-se constante durante todo o recorte. A maior parte dos artigos dessa temática volta-se para a discussão de áreas específicas, como: saúde mental/reforma psiquiátrica, saúde pública/coletiva, medicalização, assistência social, educação, formação, trabalho, segurança pública, infância/adolescência/juventude e gênero/sexualidade. A grande presença de trabalhos nesta categoria pode ser relacionada com a forte inserção dos psicólogos nas políticas públicas como campo de trabalho, principalmente desde os anos 2000, como se pode perceber a partir dos estudos de Yamamoto e Oliveira (2010) e dos levantamentos realizados pela Associação Nacional de Pesquisa e Pós-Graduação em Psicologia (ANPEPP) (BASTOS et alii., 2009) e pelo Conselho Federal de Psicologia (LHULLIER; ROSLINDO, 2013).

Pelas vias do debate sobre as políticas públicas, e mais amplamente sobre as formas de governo da população, podemos perceber também o acionamento dos discursos agenciados pelo nome "Foucault" no debate sobre Gênero/Sexualidade/Feminismo, Infância/Adolescência/Juventude e Arte/Política.

Como já ressaltado, muitas vezes os estudos presentes em um grupo também trouxeram aspectos de outros, uma vez que a produção com Michel Foucault apresenta como processos intrínsecos a objetivação e a subjetivação, relacionados às práticas de governo (não trabalhadas apenas em relação às políticas públicas, mas indo muito além delas). $\mathrm{O}$ fato de se tratar de um periódico em psicologia também tem como efeito uma relação constante dos estudos com o campo "psi" e a temática da subjetividade, mesmo quando não é o enfoque do artigo.

A partir destes apontamentos podem-se observar algumas constâncias nos usos de Michel Foucault no campo da Psicologia Social brasileira, que dizem tanto do processo de recepção do pensamento do filósofo francês em nosso país quanto da história da própria Psicologia, enquanto ciência e profissão. 


\section{Conclusões e considerações finais}

Neste trabalho, investigamos a recepção de Michel Foucault na Psicologia Social brasileira a partir de seus usos na Revista Psicologia \& Sociedade, da ABRAPSO, entre 1986 e 2017. Analisamos integralmente noventa artigos que citaram o autor com a finalidade de categorizá-los em relação às suas características gerais: ano de publicação, distribuição geográfica, vinculações institucionais das autorias, temas e delineamentos dos estudos.

Foram encontradas citações do autor durante todo o recorte temporal estabelecido, sendo a primeira em 1986, e o ano com maior frequência, 2012, em razão da publicação de um número especial decorrente do "I Colóquio Internacional Michel Foucault: a judicialização da vida", que contou com muitos psicólogos em sua composição, sendo organizado por uma psicóloga e uma socióloga.

Dentre os noventa trabalhos, apenas oito são internacionais. Os demais se ligam majoritariamente a Instituições de Ensino Superior Públicas brasileiras, especialmente das regiões Sudeste e Sul $(74,4 \%)$ - característica comum na produção científica em nosso país, que pode ser considerada reflexo de uma distribuição desigual de recursos e instituições de pesquisa (SIDONE et alii., 2016). Somando-se com as parcerias interinstitucionais com Norte e Nordeste do país, esse número sobe para 85,4\%. Dos doze trabalhos produzidos exclusivamente fora do eixo Sul-Sudeste, onze se deram a partir de 2009, ligados ao exercício docente de pesquisadores que realizaram neste eixo pelo menos parte de sua formação.

Observamos a predominância de estudos teóricos $(54 ; 60 \%)$ em relação aos empíricos (36; 40\%), como é comum da pesquisa em psicologia no Brasil (FERREIRA NETO et alii., 2017). Dentre os estudos teóricos sobressaíram-se os que se voltaram para um tema (37; $41,1 \%)$, em detrimento dos teórico-conceituais $(16 ; 17,8 \%)$ e pesquisa bibliográfica $(1 ; 1,1 \%)$. Em meio às pesquisas empíricas destacaram-se as análises documentais $(19 ; 21,1 \%)$, seguidas das pesquisas de campo $(11 ; 12,2 \%)$. Também houve a presença de relatos de experiência (5; $5,5 \%)$ e um estudo de caso $(1,1 \%)$.

A partir das leituras delimitamos sete categorias temáticas para a classificação dos artigos, quais sejam: Reflexões conceituais e Epistemológicas (23; 25,5\%), Políticas Públicas (22; 24,4\%), Reflexões sobre a Psicologia (13; 14,4\%), Subjetivação (12; 13,3\%), Gênero/Sexualidade/Feminismo (6; 6,7\%), Infância/Adolescência/Juventude (5; 5,5\%) e ArtePolítica $(4 ; 4,4 \%)$. Os que não se enquadraram em nenhuma delas foram alocados na categoria "Outros" $(5 ; 5,5 \%)$. 
Entende-se a grande presença de Reflexões Conceituais e Epistemológicas e de Reflexões sobre a Psicologia como uma característica que marca os estudos neste campo de saber, no Brasil (CRUZ; STRALEN, 2012). Enfatiza-se, porém, o forte movimento de autorreflexão sobre a Psicologia nos anos 1990, período de reformulação dos lugares institucionais a serem ocupados pelos profissionais psicólogos e de grande movimentação em torno da elaboração destes novos fazeres "psi" - muitos deles, intrinsecamente ligados à atuação nas políticas públicas (YAMAMOTO; OLIVEIRA, 2010) e nas interfaces com o problema do governo das populações, em especial no que toca às temáticas de Gênero/Sexualidade/Feminismo, Infância/Adolescência/Juventude e Arte-Política. Foucault aparece como interlocutor possível neste movimento.

As problematizações sobre a Subjetivação fazem-se bastante presentes em todas as categorias, sendo, em alguns estudos, tomadas como principal foco, tanto pela imprescindibilidade deste tema para o autor quanto para a área "psi”.

Outras investigações sobre as formas de uso dos conceitos do autor em relação a cada um destes temas devem ser realizadas para melhor compreender de que forma se dá sua apropriação em cada caso. Também se faz pertinente uma pesquisa mais assídua acerca dos currículos lattes dos autores e coautores para melhor mapear a dispersão dos usos do filósofo francês pela psicologia no Brasil, através do deslocamento de pesquisadores através das regiões do país. Mais um ponto importante a ser observado é a relação estabelecida entre pesquisadores através das orientações em Programas de Pós-Graduação, participação em Associações em comum e organização de Congressos vinculados ao tema.

As possibilidades de documentos serem analisados são extensas e este trabalho teve como objetivo apenas fornecer algumas pistas sobre a recepção de Foucault na Revista Psicologia \& Sociedade, como uma forma de vislumbrar formas de sua apropriação na Psicologia Social brasileira.

\footnotetext{
${ }^{1}$ Endereço eletrônico: https://www.abrapso.org.br/

${ }^{2}$ Endereço eletrônico: www.scielo.org

${ }^{3}$ Nove dos onze artigos publicados neste ano fazem parte do número especial dedicado à Judicialização da Vida.

${ }^{4}$ Sociólogo e historiador das ciências sociais.

${ }^{5}$ Dentre as quais, quatro Pontifícias Universidades Católicas (PUCs).

${ }^{6}$ Prefeitura, Secretaria Municipal, Conselho Regional de Psicologia e Cooperativa.

7 Trata-se do artigo produzido por Márcia Frezza (UNIFOR/UFRGS), em coautoria com Cleci Maraschin (UFRGS) e Nair Silveira dos Santos (UFRGS), publicado no ano de 2009.
} 


\footnotetext{
${ }^{8}$ Trata-se do artigo produzido por Flávia Lemos (UFPA), em coautoria com Hélio Rebello Cardoso Júnior (UNESP/Assis).

${ }^{9}$ Conselho Nacional de Desenvolvimento Científico e Tecnológico.

${ }^{10}$ Essas informações foram retiradas do minicurrículo de apresentação nas publicações da Revista, e dos resumos dos currículos lattes disponíveis na plataforma do CNPq. Não foram encontradas informações sobre os grupos de pesquisa coordenados pelos demais pesquisadores durante seus anos de publicação no periódico.
}

\section{Referências}

AQUINO, J. G. A difusão do pensamento de Michel Foucault na educação brasileira: um itinerário bibliográfico. Revista Brasileira de Educação, v. 18, n. 53, p. 301-324. abr.jun. 2013. Disponível em: http://www.scielo.br/pdf/rbedu/v18n53/04.pdf Acesso em 05 fev. 2018.

BERT, J. F. Pensar com Michel Foucault. São Paulo: Parábola, 2013.

BOMFIM, E.; FREITAS, M. F. Q.; CAMPOS, R. H. F. Fazeres em Psicologia Social. In: CONSELHO FEDERAL DE PSICOLOGIA. Psicólogo brasileiro: construção de novos espaços. Campinas, SP: Editora Alínea, 2010.

BASTOS, A.; GONDIM, S.; BORGES-ANDRADE, J. O psicólogo brasileiro: sua atuação e formação profissional. O que mudou nas últimas décadas? In: YAMAMOTO, Oswaldo; COSTA, Ana Ludmila. Escritos sobre a profissão de psicólogo no Brasil. Natal, RN: EDUFRN, 2010. Disponível em http://newpsi.bvspsi.org.br/ebooks2010/pt/Acervo_files/Escritos-prof-psicologo-no_Brasil.pdf Acesso em 26 ago. 2018

CRUZ, R. N. A produção social do conhecimento na Psicologia Social brasileira: um estudo descritivolexploratório a partir da revista Psicologia \& Sociedade. 2008. 188f. Dissertação (Mestrado em Psicologia) - Universidade Federal de Minas Gerais, Belo Horizonte, 2008. Disponível em http://www.bibliotecadigital.ufmg.br/dspace/bitstream/handle/1843/TMCB-

7Y3K6Z/a_produ_o_social_do_conhecimento_na_psicologia_social_brasileira.pdf?s equence $=1$ Acesso em 26 ago. 2018

CRUZ, R. N.; STRALEN, C. J. A produção do conhecimento na Psicologia Social brasileira: um estudo descritivo a partir da revista Psicologia \& Sociedade, 1986-1992. Psicologia \& Sociedade, v. 24, n. 1, p. 227-239, 2012. Disponível em: http://www.scielo.br/pdf/psoc/v24n1/25.pdf Acesso em 06 fev. 2018

CAVAlCANTE, L.; SILVA, A.; GOMES, C.; HÜNING, S. Foucault e a psicologia no Brasil: interlocuções e novas perspectivas. Polis e Psique, v. 6, n. 2, p. 146-165. 2016. Disponível em: http://seer.ufrgs.br/index.php/PolisePsique/article/view/63068 Acesso em 15 fev. 2017.

FERREIRA NETO, J. L.; MOREIRA, J. O.; ARAÚJO, J. N. G.; DRAWIN, C. R. Usos de Foucault nos estudos de psicologia no Brasil. Psicologia \& Sociedade, v. 29, e159930. 2017. Disponível em: http://www.scielo.br/pdf/psoc/v29/1807-0310-psoc-29e159930.pdf. Acesso em: 05 fev. 2018. 
LHULLIER, L. A.; ROSLINDO, J. As psicólogas brasileiras: levantando a ponta do véu. In: CONSELHO FEDERAL DE PSICOLOGIA. Quem é a Psicóloga Brasileira? Mulher, Psicologia e Trabalho. Brasília: CFP, 2013.

MARASCHIN, C. Editorial. Psicologia \& Sociedade, v. 19, n. 1, 2007.

SIDONE, O. J. G.; HADDAD, E. A.; MENA-CHALCO, J. P. A ciência nas regiões brasileiras: evolução da produção e das redes de colaboração científica. Transformação, Campinas, v. 28, n. 1, p. 15-31, 2016. Disponível em: http://www.scielo.br/pdf/tinf/v28n1/0103-3786-tinf-28-01-00015.pdf Acesso em 26 ago. 2019

SILVA, N. M. A. Os usos pedagógicos da noção de cuidado de si: Um estudo sobre a recepção do pensamento tardio de Michel Foucault no campo educacional brasileiro. 2012. 184f. Dissertação (Mestrado em Educação) - Universidade Federal de Pernambuco, $\quad$ Recife, $2012 . \quad$ Disponível em https://repositorio.ufpe.br/bitstream/123456789/12887/1/arquivo8955_1.pdf Acesso em 26 ago. 2018

RAMOS, I. G. Genealogia de uma operação historiográfica: Edward Palmer Thompson, Michel Foucault e os historiadores brasileiros da década de 1980. São Paulo: Cultura Acadêmica, 2015. Disponível em: http://books.scielo.org/id/p87q7/pdf/ramos9788579837067.pdf Acesso em 06 fev. 2018

RICCIO, G. L.; MENDONÇA NETO, O R.; SAKATA, M. C. G. Movimentos de Teorias em Campos Interdisciplinares: a Inserção de Michel Foucault na Contabilidade. Revista de Administração Contemporânea, v. 11, n. esp. 2, p. 11-32. 2007. Disponível em: http://www.scielo.br/pdf/rac/v11nspe2/a0211ns2.pdfAcesso em 06 fev. 2018.

YAMAMOTO, O.; OLIVEIRA, I. Política Social e Psicologia: Uma Trajetória de 25 anos. Psicologia: Teoria e Pesquisa, v. 26, n. esp., p. 9-24, 2010.

ZANELLA, A. V. Os 15 anos da ABRAPSO. 2009 [1995]. Disponível em: http://abrapso.org.br/siteprincipal/images/Documentos/osquinzesanosdaabrapso.pdf Acesso em 06 fev. 2018

Amanda Gabriella Borges Magalhães Psicóloga concursada na UFPA-Campus de Cametá-PA. Mestre em Psicologia pela UFPA, Graduada em Psicologia pela UFPA.

E-mail: amandagabriella_@hotmail.com

Flávia Cristina Silveira Lemos Profa Dra. Associada II de Psicologia Social - UFPA. E-mail: flaviacslemos@gmail.com 